\title{
Expression of TGFB1 and its receptors is associated with biological features of ovarian cancer and sensitivity to paclitaxel/carboplatin
}

\author{
SHINICHI KOMIYAMA ${ }^{1,2}$, TAKASHI KURAHASHI ${ }^{2}$, MITSUYA ISHIKAWA ${ }^{2}$, KYOKO TANAKA ${ }^{2,3}$, \\ MIZUKA KOMIYAMA $^{1}$, MIKIO MIKAMI ${ }^{2,4}$ and YASUHIRO UDAGAWA ${ }^{1}$ \\ ${ }^{1}$ Department of Obstetrics and Gynecology, Fujita Health University School of Medicine, Toyoake, Aichi 470-1192; \\ ${ }^{2}$ Department of Obstetrics and Gynecology, National Hospital Organization Saitama Hospital, Wako, Saitama 351-0102; \\ ${ }^{3}$ Department of Obstetrics and Gynecology, Keio University School of Medicine, Shinjuku, Tokyo 160-8582; \\ ${ }^{4}$ Department of Obstetrics and Gynecology, Tokai University School of Medicine, Isehara, Kanagawa 259-1193, Japan
}

Received September 16, 2010; Accepted December 2, 2010

DOI: $10.3892 /$ or.2011.1151

\begin{abstract}
It has been suggested that expression of TGFß1 and its receptors [TGFß receptor type I (TßRI) and TGFß receptor type II (TßRII)] may play a key role in the proliferation and progression of epithelial ovarian cancer. We investigated the biological significance of TGFß1 and its receptors, as well as their association with the tumor response to paclitaxel (PTX) and carboplatin (CBDCA). We studied 24 patients with ovarian cancer, primary peritoneal cancer, or fallopian tube cancer who had undergone surgery and chemotherapy with PTX and CBDCA. Tissues from the primary tumor were examined and the expression of TGFß1, TBRI, and TBRII mRNA was assessed by the RNase protection assay. It was found that TGFß1 mRNA expression was significantly lower in the tumors of patients who had optimal surgery than in the tumors of patients with suboptimal surgery. TGFß1 mRNA expression was also significantly lower in tumors with high sensitivity to PTX and CBDCA than in those with low sensitivity. TßRI mRNA expression was not associated with any clinicopathological factors. Expression of TßRII mRNA was significantly higher in clear cell adenocarcinoma and mucinous adenocarcinoma, while it was lower in serous adenocarcinoma and endometrioid adenocarcinoma. Moreover, it tended to be higher in early-stage tumors compared with advanced tumors. Among TGFß1, TßRI, and TßRII, expression of TGFß1 mRNA was most strongly associated with progression-free survival. When the prognosis
\end{abstract}

Correspondence to: Dr Shinichi Komiyama, Department of Obstetrics and Gynecology, Fujita Health University School of Medicine, Toyoake, Aichi 470-1192, Japan

E-mail: shinkomiyama@gmail.com

Key words: ovarian cancer, TGFß1, TGFß receptor, paclitaxel, carboplatin, prognosis, biomarker of the patients with advanced cancer was compared on the basis of TGFß1 mRNA expression, those whose tumors showed low expression tended to have a better prognosis than those whose tumors showed high expression. It is suggested that TGFß1 mRNA expression is an indicator of tumor sensitivity to standard therapy with PTX and CBDCA, that it can identify biologically aggressive and highly malignant tumors and that it can predict the prognosis of patients with ovarian cancer.

\section{Introduction}

Ovarian cancer is called the 'silent killer', since there is no effective diagnostic method for detecting these tumors at an early stage and more than $50 \%$ of patients have advanced disease ( $\geq$ stage III) at diagnosis (1). The standard therapy for ovarian cancer is multidisciplinary treatment that combines radical surgery or maximum tumor-debulking surgery with taxane- and platinum-based chemotherapy (2). Ovarian cancer is generally sensitive to anticancer drugs, and approximately $70 \%$ of patients can achieve remission with the standard taxane- and platinum-based chemotherapy $(3,4)$. In other words, this therapy is ineffective in about $30 \%$ of patients. Moreover, relapse is not uncommon, even if remission is achieved. In fact, approximately $70 \%$ of patients with advanced cancer experience relapse within 2 years after the initiation of treatment, and relapsing tumors are often resistant to chemotherapy $(4,5)$. Consequently, the long-term prognosis of patients with advanced ovarian cancer is poor. The biological features of tumors and their sensitivity to anticancer drugs depend on the tumor histology (6-8). Due to the limitations of current standard therapy for ovarian cancer, new treatment strategies to improve the long-term prognosis of patients with this cancer are being examined. Attempts are also being made to develop new biomarkers that can predict biological malignancy and the effectiveness of standard chemotherapy in order to establish tailor-made treatment.

Transforming growth factor-beta 1 (TGFß1) is a multifunctional secreted protein that regulates cell proliferation, 


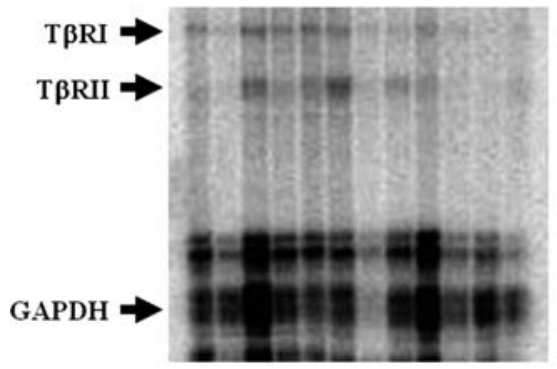

A

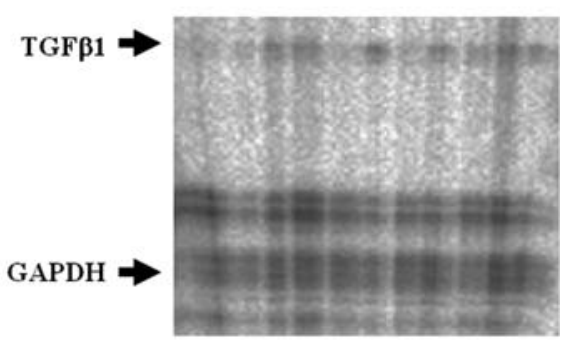

B

Figure 1. Examples of the expression of TGFß1, TGFß receptor type I (TßRI), and TGFß receptor type II (TßRII) mRNAs (RiboQuant Multi-Probe RNase protection assay system). (A) Expression of TßRI and TßRII. (B) Expression of TGFß1. GAPDH, glyceraldehyde 3-phosphate dehydrogenase.

differentiation, and motility, as well as influencing production of the extracellular matrix, neovascularization, and immune function (9-11). In addition, it was recently reported that TGFB1 has an important role in the epithelialmesenchymal transition (EMT) and strongly influences the metastasis of solid cancers (11-13). Previous studies of various solid cancers have shown that the expression of TGFß1 and its receptors, TGFß receptor type I (TßRI) and TGFß receptor type II (TßRII), is associated with tumor proliferation and progression as well as tumor sensitivity to anticancer drugs, and thus their use as biomarkers for diagnosis and treatment has been proposed (14-18). Although there have been some reports on the expression of TGFß1, TßRI, and TßRII in patients with ovarian cancer, very few studies have examined associations with the prognosis and with sensitivity to anticancer drugs.

Therefore, we evaluated the expression of TGFß1, TßRI, and TBRII in patients with ovarian cancer, and assessed associations with the prognosis, tumor biological features, and response to taxane- and platinum-based chemotherapy, in order to examine whether these are potential new biomarkers, for use in the treatment of ovarian cancer.

\section{Materials and methods}

The subjects were 24 patients with epithelial ovarian cancer, primary peritoneal cancer, or fallopian tube cancer who underwent surgery and chemotherapy with a taxane (paclitaxel: PTX) and a platinum agent (carboplatin: CBDCA) at the Department of Obstetrics and Gynecology of National Hospital Organization Saitama Hospital (NHO Saitama Hospital). Informed consent was obtained from the patients or their family members. Tissue samples obtained from the primary tumor during initial surgery were studied. Since primary peritoneal cancer and fallopian tube cancer are similar to epithelial ovarian cancer (serous adenocarcinoma) with respect to histopathological features and sensitivity to anticancer drugs, they have recently been considered as a single disease entity known as Müllerian adenocarcinoma. Therefore, patients with primary peritoneal cancer and fallopian tube cancer were also included in the present study.

The expression of TGFß1, TßRI, and TßRII mRNA was examined with the RiboQuant Multi-Probe RNase protection assay system (Pharmingen, San Diego, CA). First, total RNA was extracted by using an RNeasy mini kit (Qiagen, Valencia,
Table I. Patient profile.

Number of patients

Median age (range)

Median follow-up period (range)

Diagnosis

Epithelial ovarian cancer

Primary peritoneal cancer

Fallopian tube cancer

Tumor histology

Serous adenocarcinoma

Endometrioid adenocarcinoma

Mucinous adenocarcinoma

Clear cell adenocarcinoma

FIGO stage

I 9

II 2

III

IV

Completeness of PDS for stage III/IV tumors

Optimal

Suboptimal

Clinical sensitivity to PTX/CBDCA

High

Low

PDS, primary debulking surgery; optimal, residual tumor diameter $<1 \mathrm{~cm}$; suboptimal, residual tumor diameter $\geq 1 \mathrm{~cm}$; PTX, paclitaxel; CBDCA, carboplatin.

CA). According to the RiboQuant protocol, two multi-probe template sets (Pharmingen) were used to obtain cDNA for TGFß1 (hCK-3), as well as TßRI and TßRII (hCR-4). Then in vitro transcription was performed from the cDNA constructs using T7 RNA polymerase to create ${ }^{32} \mathrm{P}$-labeled antisense RNA probes and hybridization with total RNA extracted from each tumor. Single-stranded RNA was dissolved with 

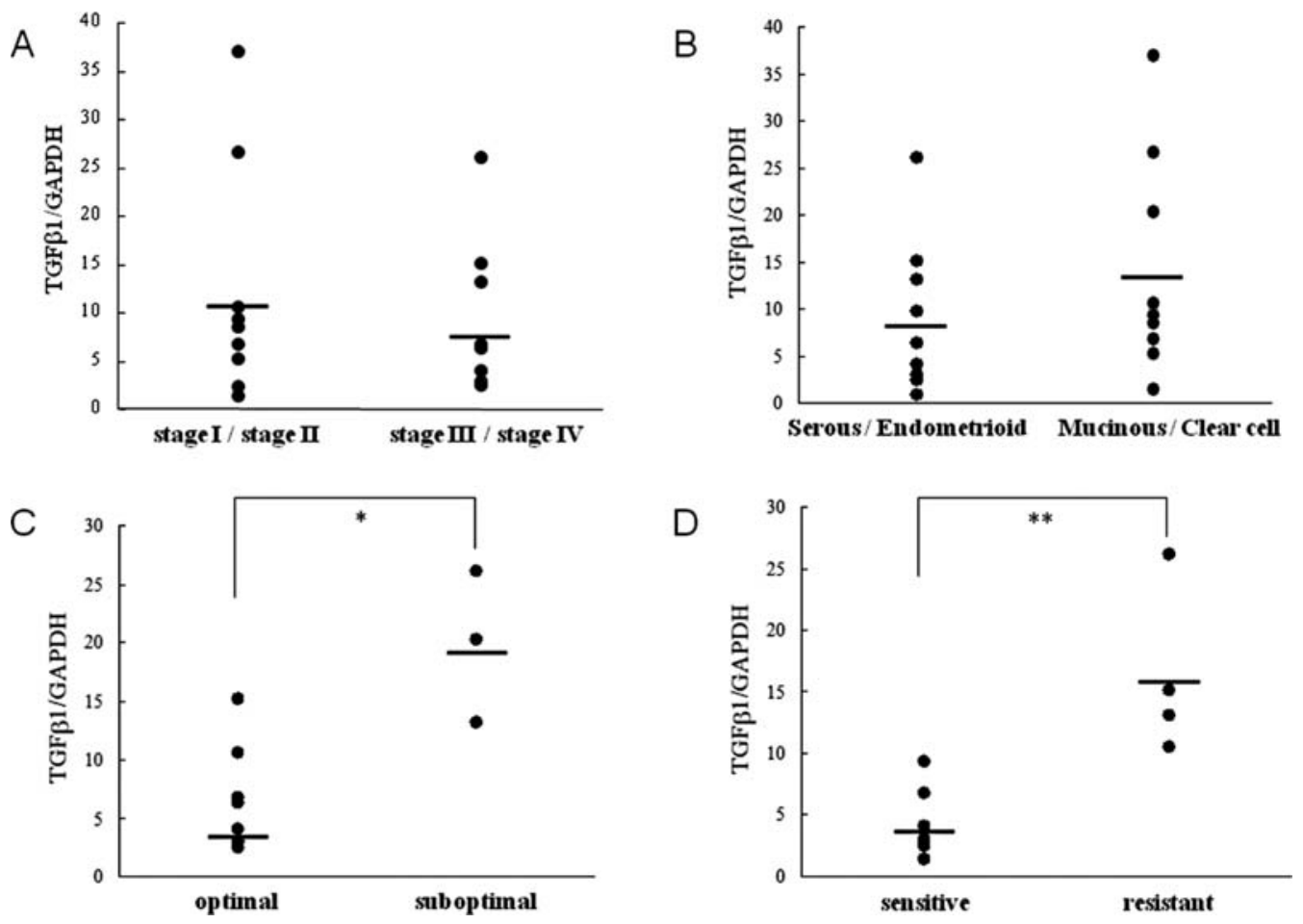

Figure 2. Association between TGFß1 mRNA expression and various clinicopathological factors. Expression of TGFß1 was higher in mucinous adenocarcinoma and clear cell adenocarcinoma, while it was lower in serous adenocarcinoma and endometrioid adenocarcinoma, but there was no significant difference (B). Expression of TGFß1 mRNA was not significantly different between early tumors (stages I and II) and advanced tumors (stages III and IV) (A). Expression of TGFß1 was lower in the tumors of patients with successful (optimal) primary surgery compared with the tumors of patients who had suboptimal surgery, and there was a significant difference $(" \mathrm{p}<0.05)(\mathrm{C})$. As for sensitivity to PTX and CBDCA, TGFß1 expression was significantly lower in tumors with a high sensitivity (sensitive) than in tumors with a low sensitivity (resistant) $(*$ p $<0.01)(\mathrm{D})$.

an RNase cocktail, followed by electrophoresis on $5 \%$ denaturing polyacrylamide gel and exposure to an imaging plate.

The mRNA bands were visualized with a FLA3000 (Fujifilm, Tokyo, Japan) and the density of each band was quantified by using Image gauge software (Fujifilm). Then mRNA expression was normalized for that of the endogenous control (glyceraldehyde-3-phosphate dehydrogenase: GAPDH) and quantified. We examined the associations between expression of TGFß1, TßRI, and TßRII mRNA and various biological tumor features or with factors influencing the prognosis of the patients, including tumor histology, the International Federation of Gynecology and Obstetrics (FIGO) stage, the completeness of primary tumor resection (amount of residual tumor), and tumor sensitivity to chemotherapy. The clinical sensitivity of tumors in stages II-IV was determined as follows: tumors that showed a complete response/ partial response to standard postoperative chemotherapy with PTX and CBDCA or did not relapse within 6 months after postoperative chemotherapy were defined as 'sensitive', while the others were classed as 'resistant'. Since the number of patients with each tumor histology was limited, serous adenocarcinoma and endometrioid adenocarcinoma (which show similar sensitivity to anticancer drugs) were grouped together, while mucinous adenocarcinoma and clear cell adenocarcinoma were grouped together. Cut-off values were also set for TGFß1, TßRI, and TßRII based on the association with sensitivity to anticancer agents in our study. Then, tumors with a level of expression above the cut-off value were defined as the 'high-expression group' and those with lower expression were classed as the 'low-expression group'.

All clinical information on the patients was obtained from the records of the Department of Obstetrics and Gynecology of NHO Saitama Hospital. For statistical analysis, Student's t-test or the $\chi^{2}$ test was employed to compare two groups. Kaplan-Meier analysis was used to calculate cumulative survival, and differences were assessed with the log-rank test. The level of statistical significance was considered to be $p<0.05$. The present study was approved by the ethics committee of NHO Saitama Hospital.

\section{Results}

Tumor tissues were assayed in all 24 patients. Representative examples of TGFß1, TßRI, and TßRII mRNA expression are presented in Fig. 1. Background data for the 24 patients are listed in Table I. Results are shown as the median \pm standard error.

Expression of TGFß1 tended to be high in clear cell adenocarcinoma and mucinous adenocarcinoma (13.2 \pm 10.6$)$, while it was low in serous adenocarcinoma and endometrioid adeno-

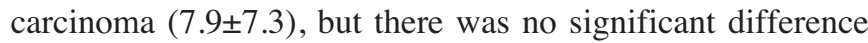
between these tumor types. The expression of TGFß1 was not significantly different between early stage tumors (stages I and II) $(11.4 \pm 23.7)$ and advanced tumors (stages III and IV) $(8.3 \pm 15.1)$. However, expression of TGFß1 was lower in the 
A

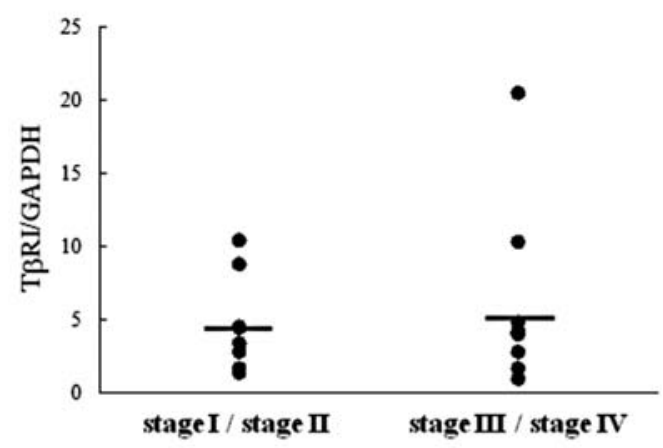

C

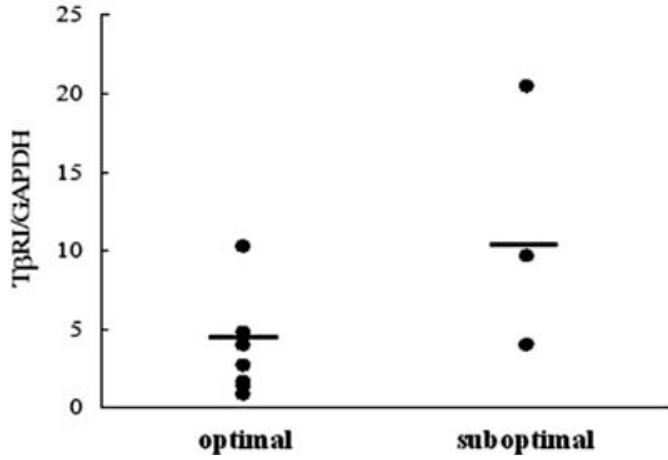

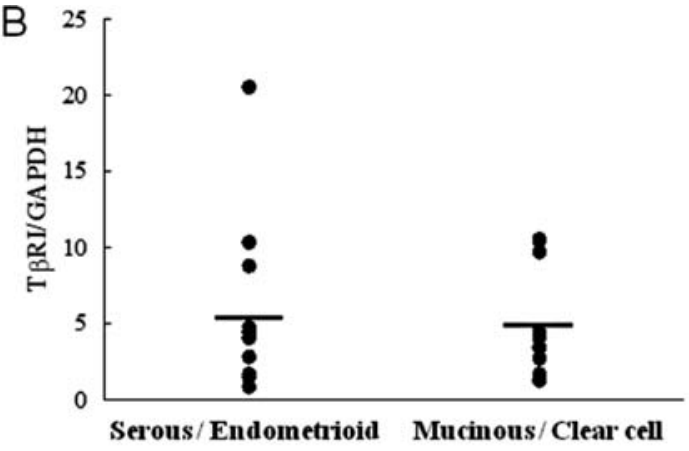

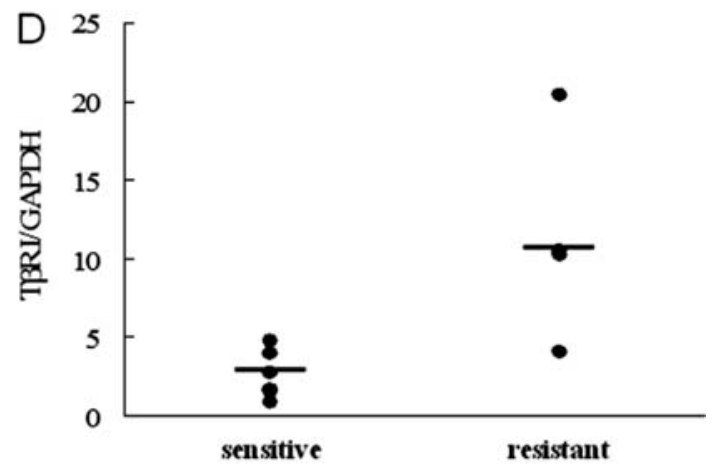

Figure 3. Association between TßRI mRNA expression and various clinicopathological factors. TßRI expression was not associated with tumor stage (A), tumor histology (B), or the completeness of primary surgery (C). However, there was lower expression in the tumors with a high sensitivity (sensitive) to PTX/CBDCA therapy than in tumors with a low sensitivity (resistant) (D).

tumors of patients who had successful (optimal) primary surgery and a residual tumor diameter $<1 \mathrm{~cm}(6.9 \pm 4.3)$ compared with patients who had suboptimal surgery and a residual tumor diameter $\geq 1 \mathrm{~cm}(18.5 \pm 7.1)$, and there was a significant difference $(\mathrm{p}=0.029)$. As for sensitivity to PTX and CBDCA, the expression of TGFß1 was significantly lower in tumors with a high sensitivity to therapy $(3.1 \pm 1.8)$ than in tumors with a low sensitivity $(16.2 \pm 6.8)(\mathrm{p}=0.0011)$ (Fig. 2).

Expression of TßRI was not associated with tumor histology, stage, or completeness of resection. However, there was lower expression of TßRI in the tumors with a high sensitivity to PTX and CBDCA $(2.7 \pm 1.4)$ than in tumors with a low sensitivity (11.3 \pm 6.8$)$ (Fig. 3).

Expression of TßII was higher in clear cell adenocarcinoma and mucinous adenocarcinoma (17.1 \pm 11.2$)$, while it was lower in serous adenocarcinoma and endometrioid adenocarcinoma (7.3 \pm 8.9$)$, and there was a significant difference $(\mathrm{p}=0.025)$. Expression of TßII tended to be higher in tumors at an early stage $(15.6 \pm 12.1)$ and lower in advanced tumors $(8.2 \pm 9.3)$. It was also low in the tumors of patients who had optimal surgery $(4.8 \pm 3.9)$, while it was high in the tumors of patients who had suboptimal surgery (17.8 \pm 11.7$)$, but there was no significant difference. Regarding sensitivity to PTX and CBDCA, expression of TßII was lower in tumors with a high sensitivity (6.2 \pm 6.6$)$ compared to those with a low sensitivity $(24.4 \pm 15.7)$ (Fig. 4).

Analysis of the association of TGFß1, TßRI, and TßRII expression with progression-free survival (PFS) revealed that the expression of TGFß1 mRNA was most strongly associated with PFS $(r=-0.805, p=0.0004)($ Fig. 5). For
TGFß1, a cut-off value was set at the median (3.1) level of expression in tumors with a high sensitivity. Then the cumulative overall survival was compared between tumors with higher expression than this cut-off value (high-TGFß1 group) and those with lower expression (low-TGFß1 group). It was found that patients with tumors showing lower expression tended to have a better prognosis, although there was no significant difference (Fig. 6).

\section{Discussion}

The standard therapy for ovarian cancer is multidisciplinary treatment that combines radical surgery or maximum tumor debulking surgery with taxane- and platinum-based chemotherapy. Particularly in patients with advanced ovarian cancer, it is extremely important to remove as much of the tumor as possible by appropriate debulking surgery, and whether primary debulking surgery is successful or not has a significant impact on the prognosis. Further improvement of the prognosis can be achieved by appropriate treatment with anticancer drugs after surgery. Nevertheless, there are limitations to surgical resection, and anticancer drugs more effective than standard taxane- and platinum-based chemotherapy have not been released for a decade (19). Consequently, the long-term prognosis of patients with ovarian cancer remains poor. Under these circumstances, it is extremely important to identify patients who are likely to respond or not respond to the current standard therapy, and to establish tailor-made treatment for those who do not respond.

Conventional pharmacodynamic indicators such as diagnostic imaging or changes of serum tumor markers may 

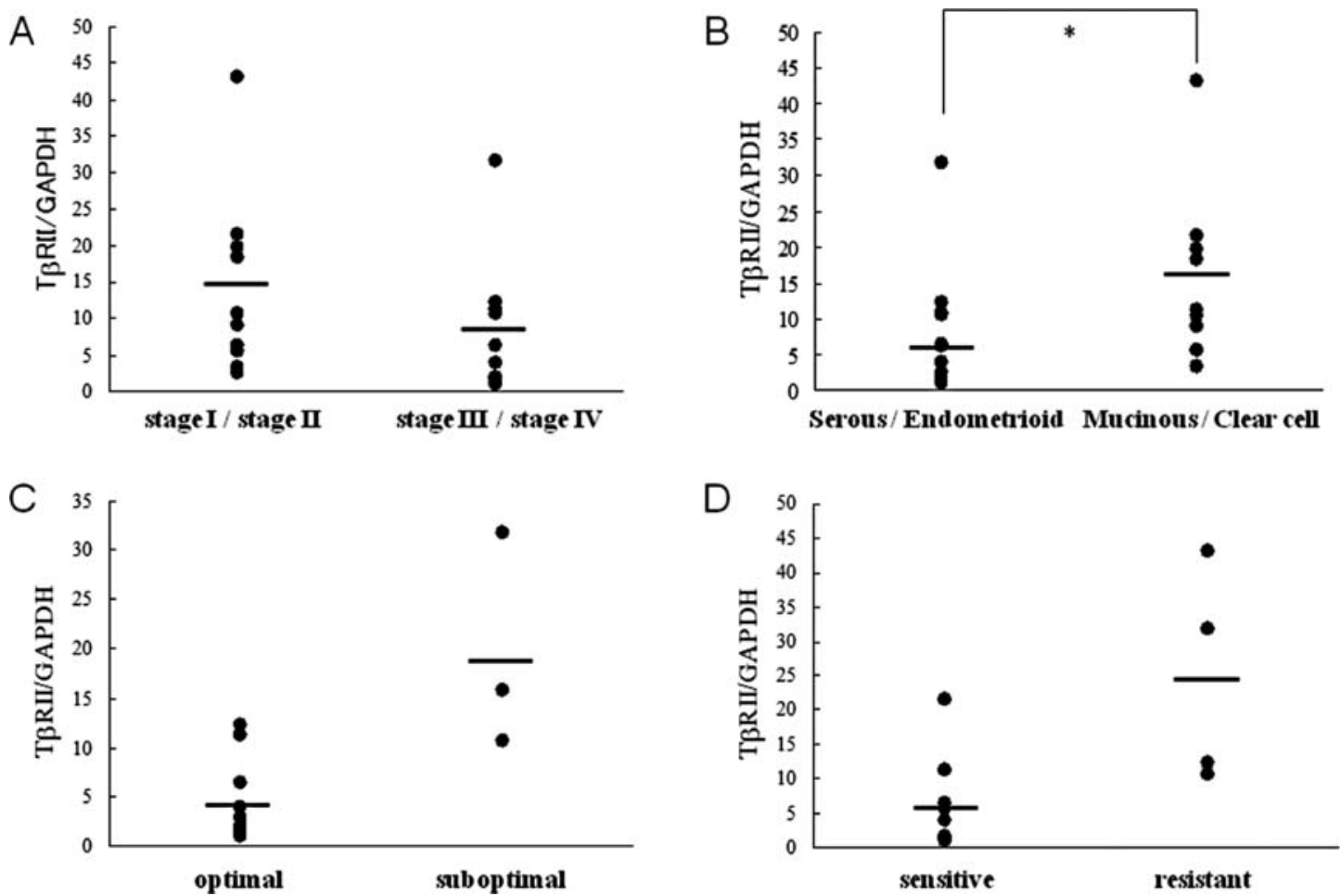

Figure 4. Association between TBRII mRNA expression and various clinicopathological factors. TBII expression was higher in tumors at an early stage (stages I and II) and lower in those at an advanced stage (stages III and IV), but there was no significant difference (A). TßII expression was higher in mucinous adenocarcinoma and clear cell adenocarcinoma, while it was lower in serous adenocarcinoma and endometrioid adenocarcinoma, and there was a significant difference ( $\left.{ }^{*} \mathrm{p}<0.05\right)(\mathrm{B})$. Moreover, it was low in the tumors of patients who had successful (optimal) primary surgery and high in the tumors of patients who had suboptimal surgery, although there was no significant difference (C). TBII expression was lower in tumors with a high sensitivity to PTX/CBDCA therapy (sensitive) than in tumors with a low sensitivity (resistant) (D).
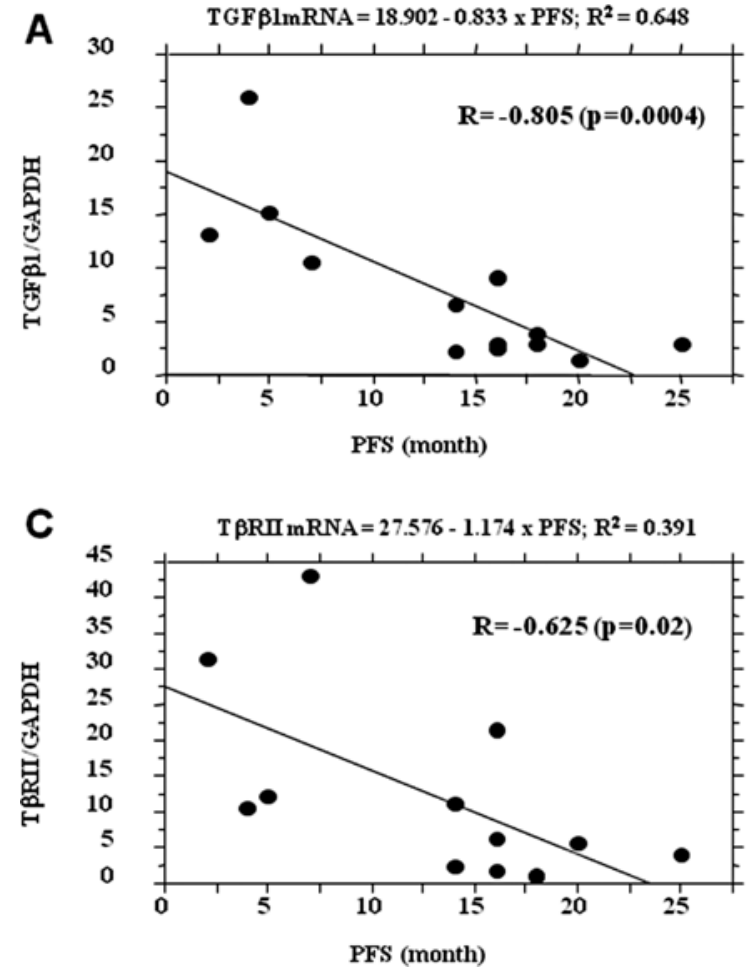

be useful to determine the short-term tumor response, but are not effective for predicting the long-term prognosis. Thus, new indicators are needed that can predict the prognosis after
B

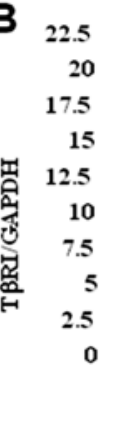

$T \beta R I m R N A=12.876-0.561 \times$ PFS $; R^{2}=0.498$

igure 5. Association of the expression of TGFß1 (A), TBRI (B), and TBRI (C) with progression-free survival (PFS). Expression of TGFß1 mRNA was most strongly associated with PFS. remission and identify patients who are not responding to standard therapy, in other words, new biomarkers to help determine treatment approaches. 


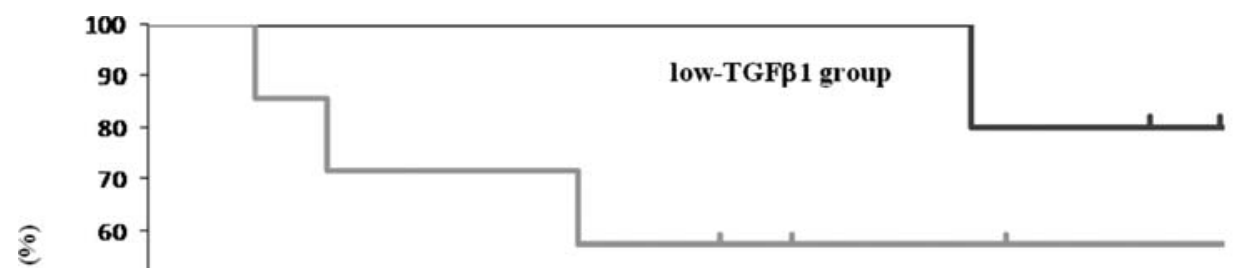

high-TGFß 1 group

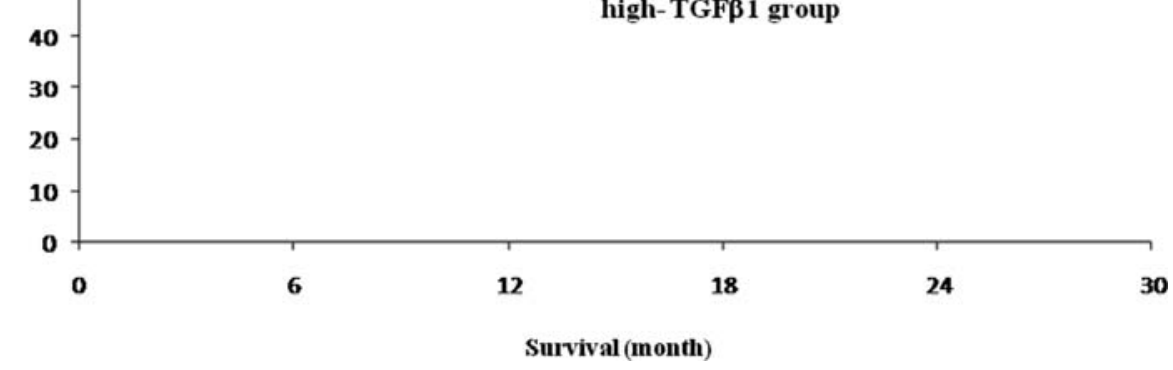

Figure 6. Comparison of the prognosis of patients with advanced cancer (stages III and IV) in relation to the expression of TGFß1. Overall survival was compared between patients whose tumors showed higher expression (high-TGFß1 group) and those whose tumors showed lower expression (low-TGFß1 group). Patients with tumors showing lower expression tended to have a better prognosis, although there was no significant difference.

It is known that TGFß1, its receptors (TßRI and TßRII), and a series of proteins in the downstream signaling cascade such as Smads are associated with the proliferation, progression, and metastasis of solid cancers. It has been reported that expression of TGFß1 is a prognostic factor for various solid cancers, is correlated with sensitivity to anticancer drugs, and is directly involved in the mechanisms of drug resistance. Therefore, TGFß1 expression is an indicator of the aggressiveness or malignancy of solid cancers. Consequently, various molecular targeting therapies for TGFß1 and its receptors are being investigated (20-22), and some have already been introduced clinically (23-29).

Although abnormalities in the expression or function of TGFß1 and its receptors, or molecules in the downstream signaling cascade, have been reported in several studies of ovarian cancer, some authors have reported significant abnormalities, while others have found minor changes and controversy exists (30-34). In addition, very few studies of ovarian cancer have assessed the associations between TGFß1 expression and the prognosis or sensitivity to anticancer drugs. Moreover, the results obtained so far have been inconsistent, with some studies of a positive association between TGFß1 expression and the prognosis (35), while other studies have found no association (36). Nevertheless, it was recently reported that, among proteins associated with the resistance of advanced ovarian serous adenocarcinoma to chemotherapy, the role of the TGFß pathway is very important (37), and that p53 and TGFß1 are key genes involved in the mechanism of resistance of ovarian cancer to platinum agents (38), Consequently, the association of TGFß1 and various molecules in its signaling cascade with the sensitivity of ovarian cancer to chemotherapy has increasingly attracted attention.

In the present study, we used the RiboQuant Multi-Probe RNase protection assay system. Although the need for a radioisotope is a disadvantage of this assay, other procedures can be undertaken easily and the results show excellent reproducibility.
We demonstrated that expression of TGFß1 was significantly lower in tumors with a high clinical sensitivity to PTX/CBDCA therapy than in tumors with a low sensitivity. Thus, it is suggested that there is a correlation between TGFß1 expression and sensitivity to standard therapy with PTX and CBDCA. Moreover, although there was no significant difference, expression of TGFß1 tended to be high in clear cell adenocarcinoma and mucinous adenocarcinoma, while it was lower in serous adenocarcinoma and endometrioid adenocarcinoma. Since it is known that clear cell and mucinous adenocarcinoma are more likely to show resistance to taxanes and platinum $(7,8)$, the results of the present study provide further evidence of a potential association between TGFß1 and the tumor response to chemotherapy. Moreover, although there was no difference in the expression of TGFß1 between early stage tumors and advanced tumors, it was significantly lower in the tumors of patients who had optimal surgery than in the tumors of patients who had suboptimal surgery, suggesting that the higher TGFß1 expression indicates a more biologically aggressive or malignant tumor.

As for the TGFß receptors, TßRI was not associated with any of the clinicopathological factors. Thus, based on the findings of the present study, the biological significance of this receptor for ovarian cancer seems to be low. On the other hand, expression of TßRII was high in clear cell adenocarcinoma and mucinous adenocarcinoma, but was low in serous adenocarcinoma and endometrioid adenocarcinoma, suggesting tissue specificity. In addition, TßRII expression tended to be higher in early tumors compared with those at an advanced stage. This is consistent with the findings of a previous study that showed down-regulation of the gene expression of TßRII in ovarian serous adenocarcinoma at an advanced stage rather than at an early stage (39). Therefore, it can be suggested that TßRII expression is correlated with the progression of ovarian cancer. Clear cell adenocarcinoma and mucinous adenocarcinoma are more likely to be detected at an early stage than at an advanced stage, which also supports the tissue specificity of TßRII expression. 
When the associations among TGFß1, TßRI, and TßRII and PFS were analyzed, it was found that TGFß1 mRNA expression was most strongly associated with PFS. Moreover, when the survival of the patients with advanced cancer was compared between those with higher and lower TGFß1 expression, the latter group had a better prognosis. Although a small number of patients was a limitation of the present study, analysis of a larger sample may reveal a significant difference. Therefore, it can be suggested that TGFß1 expression is a useful biomarker for predicting the prognosis of patients with ovarian cancer. In addition, considering that TGFß1 expression is associated with the malignancy of tumors and with sensitivity to taxanes or platinum agents, as mentioned earlier, tailor-made treatment (rather than standard therapy) may be needed for patients with tumors overexpressing TGFß1.

In summary, the present study revealed that TGFß1 can be an indicator of tumor sensitivity to standard chemotherapy (PTX and CBDCA), can identify tumors that are biologically aggressive or highly malignant, and can help to predict the prognosis of ovarian cancer patients. Consequently, it was suggested that TGFß1 may be a useful biomarker for the diagnosis and treatment of ovarian cancer. In addition, TßRII was associated with the histology and progression of ovarian cancer.

\section{Acknowledgements}

This study was supported in part by both funds from Grantsin-Aid for Scientific Research (C): 18591850 and funds from Grants-in-Aid for Challenging Exploratory Research: 21659387 to Shinichi Komiyama.

\section{References}

1. Winter WE III, Maxwell GL, Tian C, et al: Prognostic factors for stage III epithelial ovarian cancer: a Gynecologic Oncology Group Study. J Clin Oncol 25: 3621-3627, 2007.

2. Morgan RJ Jr, Alvarez RD, Armstrong DK, et al: National Comprehensive Cancer Network. Ovarian cancer. Clinical practice guidelines in oncology. J Natl Compr Canc Netw 6: 766-794, 2008

3. Herzog TJ and Pothuri B: Ovarian cancer: a focus on management of recurrent disease. Nat Clin Pract Oncol 3: 604-611, 2006.

4. Ozols RF: Challenges for chemotherapy in ovarian cancer. Ann Oncol 17 (Suppl 5): v181-v187, 2006.

5. Bukowski RM, Ozols RF and Markman M: The Management of recurrent ovarian cancer. Semin Oncol 34 (Suppl 2): 1-15, 2007.

6. Shih Ie M and Kurman RJ: Ovarian tumorigenesis: a proposed model based on morphological and molecular genetic analysis. Am J Pathol 164: 1511-1518, 2004.

7. Takano M, Kikuchi Y, Yaegashi N, et al: Clear cell carcinoma of the ovary: a retrospective multicentre experience of 254 patients with complete surgical staging. Br J Cancer 94: 1369-1374, 2006

8. Shimada M, Kigawa J, Ohishi Y, et al: Clinicopathological characteristics of mucinous adenocarcinoma of the ovary. Gynecol Oncol 113: 331-334, 2009.

9. Derynck R and Zhang YE: Smad-dependent and Smadindependent pathways in TGF-beta family signalling. Nature 425: 577-584, 2003.

10. Bierie B and Moses HL: Tumour microenvironment: TGFbeta: the molecular Jekyll and Hyde of cancer. Nat Rev Cancer 6: 506-520, 2006.

11. Massague J: TGFbeta in cancer. Cell 134: 215-230, 2008.

12. Pardali K and Moustakas A: Actions of TGF-beta as tumor suppressor and pro-metastatic factor in human cancer. Biochim Biophys Acta 1775: 21-62, 2007.
13. Do TV, Kubba LA, Du H, Sturgis CD and Woodruff TK: Transforming growth factor-beta1, transforming growth factorbeta2, and transforming growth factor-beta3 enhance ovarian cancer metastatic potential by inducing a Smad3-dependent epithelial-to-mesenchymal transition. Mol Cancer Res 6: 695-705, 2008.

14. Robson H, Anderson E, James RD and Schofield PF: Transforming growth factor beta 1 expression in human colorectal tumours: an independent prognostic marker in a subgroup of poor prognosis patients. Br J Cancer 74: 753-758, 1996.

15. Teicher BA, Ikebe M, Ara G, Keyes SR and Herbst RS: Transforming growth factor-beta 1 overexpression produces drug resistance in vivo: reversal by decorin. In Vivo 11: 463-472, 1997.

16. Bennett WP, el-Deiry WS, Rush WL, et al: p21waf1/cip1 and transforming growth factor beta 1 protein expression correlate with survival in non-small cell lung cancer. Clin Cancer Res 4: 1499-1506, 1998

17. Benson JR: Role of transforming growth factor beta in breast carcinogenesis. Lancet Oncol 5: 229-239, 2004.

18. Vagenas K, Spyropoulos C, Gavala V and Tsamandas AC: TGFbeta1, TGFbeta2, and TGFbeta3 protein expression in gastric carcinomas: correlation with prognostics factors and patient survival. J Surg Res 139: 182-188, 2007.

19. Bookman MA for the Gynecologic Cancer InterGroup (GCIG) through the Gynecologic Oncology Group (GOG): GOG182ICON5: 5-arm phase III randomized trial of paclitaxel $(\mathrm{P})$ and carboplatin (C) vs combinations with gemcitabine (G), PEGliposomal doxorubicin (D), or topotecan (T) in patients (pts) with advanced-stage epithelial ovarian (EOC) or primary peritoneal (PPC) carcinoma. J Clin Oncol 24 (Suppl): 456 , 2006.

20. Gil-Guerrero L, Dotor J, Huibregtse IL, et al: In vitro and in vivo down-regulation of regulatory $\mathrm{T}$ cell activity with a peptide inhibitor of TGF-beta1. J Immunol 181: 126-135, 2008.

21. Korpal M and Kang Y: Targeting the transforming growth factor-beta signalling pathway in metastatic cancer. Eur J Cancer 46: 1232-1240, 2010.

22. Nagaraj NS and Datta PK: Targeting the transforming growth factor-beta signaling pathway in human cancer. Expert Opin Investig Drugs 19: 77-91, 2010.

23. Halder SK, Beauchamp RD and Datta PK: A specific inhibitor of TGF-beta receptor kinase, SB-431542, as a potent antitumor agent for human cancers. Neoplasia 7: 509-521, 2005.

24. Bandyopadhyay A, Agyin JK, Wang L, et al: Inhibition of pulmonary and skeletal metastasis by a transforming growth factor-beta type I receptor kinase inhibitor. Cancer Res 66: 6714-6721, 2006

25. Ehata S, Hanyu A, Fujime M, et al: Ki26894, a novel transforming growth factor-beta type I receptor kinase inhibitor, inhibits in vitro invasion and in vivo bone metastasis of a human breast cancer cell line. Cancer Sci 98: 127-133, 2007.

26. Hau P, Jachimczak P and Bogdahn U: Treatment of malignant gliomas with TGF-beta2 antisense oligonucleotides. Expert Rev Anticancer Ther 9: 1663-1674, 2009.

27. Zhang B, Halder SK, Zhang S and Datta PK: Targeting transforming growth factor-beta signaling in liver metastasis of colon cancer. Cancer Lett 277: 114-120, 2009.

28. Nemunaitis J, Nemunaitis M, Senzer N, et al: Phase II trial of Belagenpumatucel-L, a TGF-beta2 antisense gene modified allogeneic tumor vaccine in advanced non small cell lung cancer (NSCLC) patients. Cancer Gene Ther 16: 620-624, 2009.

29. Shinto O, Yashiro M, Kawajiri H, et al: Inhibitory effect of a TGFbeta receptor type-I inhibitor, Ki26894, on invasiveness of scirrhous gastric cancer cells. Br J Cancer 102: 844-851, 2010.

30. Cardillo MR, Yap E and Castagna G: Molecular genetic analysis of TGF-betal in ovarian neoplasia. J Exp Clin Cancer Res 16: 49-56, 1997.

31. Lynch MA, Nakashima R, Song H, et al: Mutational analysis of the transforming growth factor beta receptor type II gene in human ovarian carcinoma. Cancer Res 58: 4227-4232, 1998.

32. Wang D, Kanuma T, Mizunuma H, et al: Analysis of specific gene mutations in the transforming growth factor-beta signal transduction pathway in human ovarian cancer. Cancer Res 60: 4507-4512, 2000

33. Chen T, Triplett J, Dehner B, et al: Transforming growth factorbeta receptor type I gene is frequently mutated in ovarian carcinomas. Cancer Res 61: 4679-4682, 2001. 
34. Francis-Thickpenny KM, Richardson DM, van Ee CC, et al: Analysis of the TGF beta functional pathway in epithelial ovarian carcinoma. Br J Cancer 85: 687-691, 2001.

35. Nakanishi Y, Kodama J, Yoshinouchi M, et al: The expression of vascular endothelial growth factor and transforming growth factor-beta associates with angiogenesis in epithelial ovarian cancer. Int J Gynecol pathol 16: 256-262, 1997.

36. Sonmezer M, Gungor M, Ensari A and Ortac F: Prognostic significance of tumor angiogenesis in epithelial ovarian cancer: in association with transforming growth factor beta and vascular endothelial growth factor. Int J Gynecol Cancer 14: 82-88, 2004

37. Carey MS, Agarwal R, Gilks B, et al: Functional proteomic analysis of advanced serous ovarian cancer using reverse phase protein array: TGF-beta pathway signaling indicates response to primary chemotherapy. Clin Cancer Res 16: 2852-2860, 2010
38. Helleman J, Jansen MP, Burger C, van der Burg ME and Berns EM: Integrated genomics of chemotherapy resistant ovarian cancer: a role for extracellular matrix, TGFbeta and regulating microRNAs. Int $\mathrm{J}$ Biochem Cell Biol 42: 25-30, 2010.

39. Sunde JS, Donninger H, Wu K, et al: Expression profiling identifies altered expression of genes that contribute to the inhibition of transforming growth factor-beta signaling in ovarian cancer. Cancer Res 66: 8404-8412, 2006. 